\title{
Do locked doors in psychiatric hospitals prevent patients from absconding?
}

\author{
Undine E. Lang, MD, PhD* \\ Susanne Hartmann* \\ Sandra Schulz-Hartmann ${ }^{\star \star}$ \\ Yehonala Gudlowski* \\ Roland Ricken, MD* \\ Ingrid Munk, MD, PhD** \\ Dorothea von Haebler, MD* \\ Juergen Gallinat, MD, PhD* \\ Andreas Heinz, MD, PhD* \\ * Department of Psychiatry and \\ Psychotherapy, Charité - University \\ Medicine Berlin, Campus Mitte \\ ** Department of Psychiatry and \\ Psychotherapy, Vivantes Klinikum Neukölln, \\ Berlin
}

GERMANY

\begin{abstract}
Background and Objectives: In the acute treatment of acute psychiatric patients coercive measures are often required and therapeutic relationships can be affected by such measures. In this study we assessed whether opening the entrance door of an acute psychiatric ward influences absconding behaviour.

Methods: An acute psychiatric ward was primarily closed (91.4\%) for six months and primarily open $(75.6 \%)$ for six months over the time period of one year. In this one year period, 337 patients were treated (206 male, age: $40 \pm 16$ years): $60.2 \%$ of the patients had schizophrenia, $13.6 \%$ had affective disorders, $11.6 \%$ suffered from addiction and $14.5 \%$ displayed other diagnoses.

Results: In terms of age $(\mathrm{t}=0.026, \mathrm{df}=335, \mathrm{p}=0.979)$, gender $\left(\mathrm{chi}^{2}=1.6, \mathrm{df}=1, \mathrm{p}=0.13\right)$, diagnoses $\left(\mathrm{chi}^{2}=7.337, \mathrm{df}=1, \mathrm{p}=0.062\right)$ and duration of stay $(\mathrm{t}=-0.90, \mathrm{df}=335, \mathrm{p}=0.928)$, we found no significant differences between the patients admitted in the closed and those admitted in the open ward period. Absconding $\left(\mathrm{df}=1, \mathrm{chi}^{2}=5.107, \mathrm{p}=0.029\right)$, aggressive incidents $\left(\mathrm{chi}^{2}=4.46, \mathrm{df}=1, \mathrm{p}=0.050\right)$ and coercive medications $\left(\mathrm{chi}^{2}=4.646, \mathrm{df}=1, \mathrm{p}=\right.$ 0.037 ) were observed significantly more often in the closed door period. Moreover, the duration up to readmission was reduced in the closed time period $(\mathrm{t}=2.314, \mathrm{df}=54, \mathrm{p}=0.025)$.

Conclusions: We hypothesize that open doors reduce patient's discomfort, improve ward atmosphere and aggressive acts and do not appear to increase the risk of absconding.
\end{abstract}




\section{Introduction}

Entrance doors to wards where psychiatric care is provided are often locked, which is not the case with wards where somatic care is provided. A recent review suggested that increasingly more modern inpatient wards are being kept permanently locked, even though this appears to be contrary to the current Mental Health Act Code of Practice $^{1}$. One study showed that even acute psychiatric wards with a selective open door policy are closed on up to $86 \%$ of treatment days ${ }^{2}$. While reasons to lock a ward usually point to patient's safety, literature on locked doors in inpatient psychiatric wards is inconclusive regarding the effects of this practice [for review see 1]. The most frequent argument for closing the doors in psychiatric hospitals is the prevention of absconding, followed by aggressive or suicidal behaviour of patients ${ }^{3}$. However, one study suggested that threatening events after absconding seem to happen rarely ${ }^{4}$. Indeed about $13-38 \%$ patients leave the unit without the permission of staff ${ }^{4,5}$. Moreover, patients seem to wait until they have their first chance to leave, and after coercive measures are ceased, up to $50 \%$ of those absconding from closed wards did not return from their first permitted leave $\mathrm{e}^{4,6-10}$.

Absconding of patients disrupts the therapeutic climate of the psychiatric unit ${ }^{11}$ and can be moreover a source of guilt, frustration, anger, concern or embarrassment in mental health professionals who care for these patients ${ }^{4,12}$. However, wards can be locked in the absence of committed patients and can be open in the presence of committed patients ${ }^{3}$. In this study we were mainly interested in the effect of an open door on absconding and aggressive incidents.

\section{Materials and methods}

An acute psychiatric ward was primarily closed for six months and primarily opened for six months over one year. In this time period we evaluated post-hoc the newly introduced "open-door" policy. In this time period 337 patients (206 male, age: $40 \pm 16$ years) were treated. In the first six months the entrance door was open on $8.6 \%$ of days, in the second time period the door was open on $75.6 \%$ of days. Of the patients, $60.2 \%$ were diagnosed with schizophrenia, $13.6 \%$ with affective disorders, $11.6 \%$ suffered from addiction and $14.5 \%$ displayed other diagnoses. The therapeutic setting did not change, i.e. cognitive behavioural groups were offered three times a week and a psychodynamic orientated group, running group, relaxation group and social competency training were offered once a week by the same psychologist over the whole time period. Diagnoses were made according to the 10th revision of the International Statistical Classification of Diseases and Related Health Problems. The acute unit studied in this pilot approach handles all admissions from the area "Bezirk Berlin Mitte". With 6.42 beds available per 10,000 inhabitants, Berlin's bed capacity for psychiatric patients is one of the lowest in Germany. Of the 12 different areas (regional service provisions) in Berlin, the hospital ("Berlin Mitte") is among those with the lowest bed capacities. About $20 \%$ of the patients treated are legally committed. The social structure of the population in "Bezirk Mitte" is one of the weakest in Berlin and according to recent statistics of the Berlin police department, all acts of violence, force, murder and thefts are highest in this city area.

"Absconding" was defined as staying absent without leave for more than 24 hours and leaving against medical advice, i.e. 
when a patient left against the express advice of the ward psychiatrist. "Coercive medication" was defined as forced oral or intramuscular medication in the presence of staff members. "Aggressive incidents" were defined as massive physical attacks of the patient on staff members or patients.

Data were collected retrospectively. Analyses were computed using statistical software (PASW 14.0 $\left.{ }^{\circledR}\right)$. Group differences were calculated with the chi-quare test or t-test for independent samples, specific tests used were indicated in the table.

\section{Results}

176 patients (111 male, age: $39.9 \pm 15)$ were admitted in the closed period, 161 patients (97 male, age: $40 \pm 17$ ) in the open period. The duration of stay was $18.8 \pm 23$ days in the closed and $18.6 \pm 21$ days in the open time period $(\mathrm{t}=-0.09, \mathrm{df}=335, \mathrm{p}=0.928)$ (see table 1).
In terms of age $(\mathrm{t}=0.026, \mathrm{df}=335, \mathrm{p}=$ $0.979)$, gender $\left(\operatorname{chi}^{2}=1.6, \mathrm{df}=1, \mathrm{p}=0.13\right)$, diagnoses $\left(\mathrm{chi}^{2}=7.337, \mathrm{df}=1, \mathrm{p}=0.062\right)$ and duration of stay $(\mathrm{t}=-0.90, \mathrm{df}=335, \mathrm{p}=$ 0.928) we found no significant differences between the patients admitted in the closed and those admitted in the open ward period.

During the whole one year period, 57 $(17 \%)$ patients left the unit without permission, 22 of them in the open and 35 in the closed time period. Absconders' diagnoses were: addictive disorders ( 7 patients), schizophrenia (36 patients), affective disorders ( 9 patients) and other diagnoses (5 patients).

Absconders in our sample tended to be male (44 male versus 13 female patients) $\left(\mathrm{chi}^{2}=7.452, \mathrm{df}=1, \mathrm{p}=0.007\right)$ and significantly younger than non-absconders $(41 \pm$ 16 versus $34 \pm 10$ years $)(t=2.9, d f=127, p$ $=0.004)$. The results of our study thereby confirm most of the findings from the literature $^{3,4}$. Absconding was observed significantly more often in the closed time period $\left(\mathrm{chi}^{2}=5.107, \mathrm{df}=1, \mathrm{p}=0.029\right)$ and the time

Table 1

\begin{tabular}{|c|c|c|c|c|}
\hline & Closed $91 \%$ & Open $75 \%$ & $\mathrm{t} / \mathrm{chi}^{2}$ & Significance \\
\hline Patients (n) & 176 & 161 & & \\
\hline Gender (male) & 111 & 97 & $1.6^{1}$ & n.s. ${ }^{1}$ \\
\hline Age (years $\pm \mathrm{SD})$ & $39.9 \pm 15$ & $40 \pm 17$ & $0.026^{2}$ & n.s. ${ }^{2}$ \\
\hline Diagnoses & & & $7.33^{1}$ & n.s. ${ }^{1}$ \\
\hline Duration of stay (days \pm SD) & $18.8 \pm 23$ & $18.6 \pm 21$ & $-0.90^{2}$ & n.s. ${ }^{2}$ \\
\hline Absconders $(n=57)$ & 35 & 22 & $5.107^{1}$ & $\mathrm{p}=0.029^{1}$ \\
\hline Interval to readmission (days \pm SD) & $9 \pm 9$ & $26 \pm 34$ & $2.314^{2}$ & $\mathrm{p}=0.025^{2}$ \\
\hline Aggressive incidents $(\mathrm{n}=36), 319$ patients included & 23 & 13 & $4.46^{1}$ & $\mathrm{p}=0.050^{1}$ \\
\hline Suicides (n) & 2 & 0 & $2.2^{1}$ & n.s. ${ }^{1}$ \\
\hline $\begin{array}{l}\text { Instances of Coercive Medication } \\
(\mathrm{n}=25), 319 \text { patients included }\end{array}$ & 17 & 8 & $4.646^{1}$ & $\mathrm{p}=0.037^{1}$ \\
\hline
\end{tabular}

${ }^{1}=\mathrm{Chi}^{2}, \mathrm{Chi}^{2}$-test.

$2=\mathrm{t}$, t-test. 
interval to readmission was reduced in the closed time period $(\mathrm{t}=2.314, \mathrm{df}=54, \mathrm{p}=$ $0.025)$. In this one year period, 25 instances of coercive medication and 36 aggressive incidents were noted retrospectively in the patients' files $(n=319)$. Significantly more coercive treatments $\left(\mathrm{n}=319, \mathrm{chi}^{2}=4.646, \mathrm{df}=\right.$ $1, \mathrm{p}=0.037)$ and aggressive incidents $(\mathrm{n}=$ $319, \mathrm{chi}^{2}=4.460, \mathrm{df}=1, \mathrm{p}=0.050$ ) were observed in the closed period. During the one year period, two inpatient suicides occurred, both in the closed period (see table 1).

\section{Discussion}

In this study, we found no evidence that a closed entrance door reduces absconding. In contrast, we found a significantly reduced absconding rate in the time period during which the entrance door was mostly open. To the best of our knowledge, this is the first study showing the effects of opening doors in an otherwise unchanged therapeutic setting.

One study showed that the majority of abscondings from closed wards occurs after patients have been given permission to leave the ward unaccompanied ${ }^{4}$. A recent review suggested that about $20 \%$ of abscondings happen, while patients are restricted to the unit, doors are locked, and staff is stationed at the doors 5 . The safety factor "closed door" might therefore be overestimated.

Absconders often refer to feeling disturbed by other patients, feeling stigmatized by being on a closed unit, missing interesting activities and being concerned about issues at home as the major factors influencing their decision to go absent without leave ${ }^{4}$. These motives to leave point to the importance of offering patients less stigmatizing treatment options and more possibilities to retreat and leave. Moreover, a general closing of doors in psychiatric hospitals might increase prejudice and stigmatization of schizophrenic patients ${ }^{13}$. Indeed, it has been argued that the chronic exposure to the stigma of being on a closed unit might increase the risk of relapse, poor compliance and depression in schizophrenic patients ${ }^{14}$. Moreover, the prevalence of violence among subjects with schizophrenia who do not abuse substances is indistinguishable from that among their neighbourhood controls ${ }^{15}$, suggesting that general policies of danger control via closed doors cannot be based on the diagnosis of schizophrenia in a majority of patients.

Closing the doors of psychiatric units might increase aggressive incidents, as was observed in our study. This hypothesis appears to be supported by the fact that ward crowding was found to be significantly associated with aggressive incidents ${ }^{16}$ and increased absconding rates have been connected to a punitive or threatening atmosphere on an inpatient unit ${ }^{5}$. In a study by Falkowski et al. ${ }^{17}, 19 \%$ of absconders referred to being disturbed by other patients as a reason for leaving the ward. A further $17 \%$ described the stigma of being on a closed ward as a major factor influencing their decision to go absent without leave. Other reasons reported were: disliking the staff $(13 \%)$, the food $(11 \%)$, the ward $(8 \%)$, lack of privacy (7\%) and responding to hallucinations (5\%). These data suggest that the personal freedom associated with an open door might prevent patients from absconding. Locked entrance doors in psychiatric wards might be experienced by patients as confinement, forced dependence on the staff and emotional distress ${ }^{21}$. Indeed, the need for the staff to maintain control is often given as an argument for closing psychiatric entrance doors ${ }^{3}$. In line with this, evidence suggests that personality, stress, and burnout of nursing staff 
are predictive of incidents on closed psychiatric wards, i.e. a restrictive attitude might provoke incidents and absconding behaviour $^{22,23}$. We did not systematically examine the patients` attitude during the open versus the closed door period; however, several patients personally communicated to us how much they appreciated the open setting.

As the clinician-patient relationship is among the strongest factors for adherence to therapy in schizophrenic patients ${ }^{28,29}$ an open door strategy might increase adherence. In our study a significantly shorter interval up to readmission in the closed time period suggests that increased non-adherence following discharge from the hospital is associated with the closed door. In line with our finding it has been shown that general satisfaction, satisfaction with medication, ward equipment, visiting opportunities, and regulations for going out are significantly lower at discharge on a closed ward ${ }^{30}$.

The most important aspect of an open door might be a better rapport between patients and treatment staff and a less restrictive attitude on the part of the staff. Accordingly, one study showed that the best staffed ward with the most experienced staff had the lowest rate of irregular discharges, and the ward with the least experienced medical staff had the second highest rate of irregular discharges, $43 \%$ of which were absent without leave ${ }^{24}$. In line with this hypothesis, several studies noted that patients who were admitted during weekend shifts, when staffing and staffing continuity are reduced, had an increased likelihood of being discharged against medical advice ${ }^{25-27}$. However, these aspects highlight also the limitations of our study. Firstly, a psychotherapeutic setting is rather unusual in acute psychiatry, and although this setting did not change during the two time periods, the increased psychological support for patients might have held them back from leaving the unit in both periods.
In Germany, the law requires that a patient is supervised 1:1 whenever he or she is fixated to the bed during coercive treatment. During the open period, coercive measures were occurring less frequently so we used the personal, who was now no longer required to supervise coercive treatment to guard the door or accompany single suicidal patients. This factor may have contributed to reduce coercive treatment incidents during the open door period.

Altogether, we hypothesize that closed doors in psychiatric hospitals do not improve the safety of patients, as the risk of absconding, aggressive acts and coercive measures were decreased with an open door policy. Our study suggests that opening the door unless otherwise required and achieving a good patient-staff rapport can reduce absconding and improve treatment effects.

\section{Acknowledgements}

The work of Undine E. Lang was supported by the DFG Deutsche Forschungsgemeinschaft (LA 2694/1-2). We thank Mrs Aubel for the excellent linguistic revision of the manuscript.

\section{Disclosure/ Conflicts of Interest}

The authors declare that, except for income received from their primary employer, no financial support or compensation has been received from any individual or corporate entity over the past 12 months for research or professional service related to this study and there are no personal financial holdings that could be perceived as constituting a potential conflict of interest. 


\section{References}

1. Van der Merwe M, Bowers L, Jones J, Simpson A, Haglund K. Locked doors in acute inpatient psychiatry: A literature review. J Psychiatr Ment Health Nurs 2009; 16: 293-299.

2. Neuenschwander M, Meyer PC, Hell D. Verlauf und Einflussfaktoren der Öffnungszeiten von teiloffen geführten psychiatrischen Akutstationen. Schweiz Arch Neurol Psychiatr 2003; 154: 20-27.

3. Haglund K, van der Meiden E, von Knorring L, von Essen L. Psychiatric care behind locked doors. A study regarding the frequency of and the reasons for locked psychiatric wards in Sweden. J Psychiatr Ment Health Nurs 2007; 14: 49-54.

4. Meehan T, Morrison P, McDougall S. Absconding behaviour: an exploratory investigation in an acute inpatient unit. Aust N Z J Psychiatry 1999; 33: 533-537.

5. Bowers L, Jarrett M, Clark N. Absconding: A literature review. J Psychiatr Ment Health Nurs 1998; 5: 343-353.

6. Chandrasena RD. Premature discharges: a comparative study. Can J Psychiatry 1987; 32: 259-263.

7. Conroy T, Jorgensen J. Decreasing elopement through interdisciplinary teamwork. Nurs Qual Connect 1995; 5: 30-31.

8. Molnar G, Keitner L, Swindall L. Medicolegal problems of elopement from psychiatric units. J Forensic Sci 1985; 30: 44-49.

9. Richmond I, Dandridge L, Jones K. Changing nursing practice to prevent elopement. J Nurs Care Qual 1991; 6: 73-81.

10. Smith HH Jr. Discharge against medical advice (AMA) from an acute care private psychiatric hospital. J Clin Psychol 1982; 38: 550-554.

11. Schulman R, Kende B. A study of runaways from a shortterm diagnostic centre. Resid Treat Child Youth 1988; 4: 11-31.

12. McIndoe K. Elope. Why psychiatric patients go AWOL. J Psychosoc Nurs Ment Health Serv 1986; 26: 16-20.

13. Jorm AF, Griffiths KM. The public's stigmatizing attitudes towards people with mental disorders: how important are biomedical conceptualizations? Acta Psychiatr Scand 2008; 118: 315-321.

14. Van Zelst C. Stigmatization as an Environmental Risk in Schizophrenia: A User Perspective. Schizophr Bull 2009; 35: 293-296.

15. Vita A. Violence and schizophrenia: commentary. Schizophr Res 2007; 94: 377-378.

16. Ng B, Kumar S, Ranclaud M, Robinson E. Ward crowding and incidents of violence on an acute psychiatric inpatient unit. Psychiatr Serv 2001; 52: 521-525.
17. Falkowski J, Watts V, Falkowski W, Dean T. Patients leaving hospital without the knowledge or permission of staff-absconding. Br J Psychiatry 1990; 156: 488-490.

18. De Hert M, McKenzie K, Peuskens J. Risk factors for suicide in young people suffering from schizophrenia: a longterm follow-up study. Schizophr Res 2001; 47: 127-134.

19. Tandon R. Suicidal behavior in schizophrenia. Expert Rev Neurother 2005; 5: 95-99.

20. Wolfersdorf M, Franke C. Suicidality - suicide and suicide prevention. Fortschr Neurol Psychiatr 2006; 74: 400-414.

21. Haglund K, von Essen L. Locked entrance doors at psychiatric wards - advantages and disadvantages according to voluntarily admitted patients. Nord J Psychiatry 2005; 59: 511-515.

22. Decaire MW, Bédard M, Riendeau J, Forrest R. Incidents in a psychiatric forensic setting: association with patient and staff characteristics. Can J Nurs Res 2006; 38: 68-80.

23. Morrison E. Tradition of toughness. Image 1990; 22: $32-38$.

24. Siegel RL, Chester TK, Price DB. Irregular discharges from psychiatric wards in a VA medical center. Hosp Community Psychiatry 1982; 33: 54-56.

25. Beck NC, Shekim W, Fraps C, Borgmeyer A, Witt A. Prediction of discharges against medical advice from an alcohol and drug misuse treatment program. J Stud Alcohol 1983; 44: 171-180.

26. Chandrasena R, Miller WC. Discharges AMA and AWOL. A new "revolving door syndrome". Psychiatr J Univ Ott 1988; 13: 154-157.

27. Louks J, Mason J, Backus F. AMA discharges: prediction and treatment outcome. Hosp Community Psychiatry 1989; 40: 299-301.

28. Fakhoury WK, White I, Priebe S, PLAO Study Group. Be good to your patient: how the therapeutic relationship in the treatment of patients admitted to assertive outreach affects rehospitalization. J Nerv Ment Dis 2007; 195: 789-791.

29. Masand PS, Narasimhan M. Improving adherence to antipsychotic pharmacotherapy. Curr Clin Pharmacol 2006; 1: $47-56$

30. Müller MJ, Schlösser R, Kapp-Steen G, Schanz B, Benkert O. Patients' satisfaction with psychiatric treatment: comparison between an open and a closed ward. Psychiatr Q 2002; 73: 93-107.

Address for correspondence:

Undine E. Lang MD, PhD

Department of Psychiatry and Psychotherapy

Charité University Medicine Berlin

Campus Mitte, Charitéplatz. 1. 10117 Berlin

Phone: 0049-30-450-617011

Fax: 0049-30-450-517944 